\title{
METABOLIC ASPECTS OF THE REGULATION OF VOLUNTARY FOOD INTAKE AND APPETITE
}

\section{J. M. FORBES}

Department of Animal Physiology and Nutrition, University of Leeds, Leeds LS2 9JT

\section{CONTENTS}

INTRODUCTION.

THE CYCLICAL NATURE OF FEEDING . . . . . . . . . 146

THE PERIOD JUST BEFORE A MEAL . . . . . . . . . . . 146

THE MEAL BEGINS . . . . . . . . . . . . . . . . . . . 148

THE MEAL CONTINUES AND TERMINATES . . . . . . . . . . . . 149

DIGESTIVE AND METABOLIC EVENTS UNDERLYING FEEDING CONTROL. . . . . . . . . . . . . . . 149

DigeSTA FLOW AND Distension OF THE DIGESTIVE TRACT • • . 149

Stomach . . . . . . . . . . . . . . . . . . 149

Duodenum. . . . . . . . . . . . . . . . . . 150

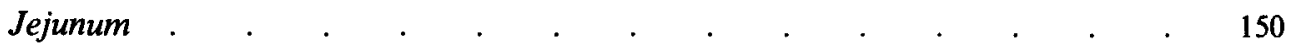

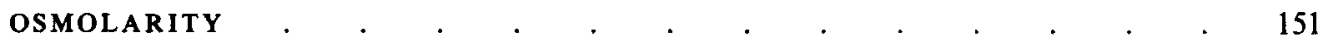

CARBOHYDRATE METABOLISM . . . . . . . . . . . . . 151

Glucose . . . . . . . . . . . . . . 151

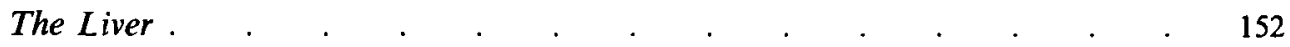

INVOLVEMEN T OF HORMONES . . . . . . . . . . . . . . . . 155

Insulin . . . . . . . . . . . . . . . . . . . . 155

Glucagon . . . . . . . . . . . . . . . 155

Gut Peptides , . . . . . . . . . . . . . . . . 157

Catecholamines. . . . . . . . . . . . . . . . . 157

FAT METABOLISM

Glycerol . . . . . . . . . . . . . . . . . 158

Ketones .

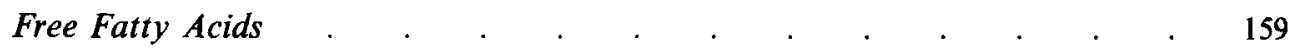

INTEGRATION OF CONTROL MECHANISMS . . . . . . . . 159

INVOLVEMENT OF THE CENTRAL NERVOUS SYSTEM . . . . . . . 159

DIET SELECTION IN RELATION TO METABOLISM • . . . . . . . 160

INTEGRATION OF SATIETY SIGNALS . . . . . . . . . . . . 161

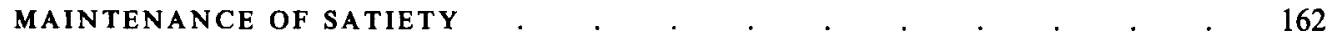

PROBLEMS AND PITFALLS . . . . . . . . . . . . . . . . 162

CONCLUSIONS . . . . . . . . . . . . . . . . . . . . . 163

REFERENCES . . . . . . . . . . . . . 163 


\section{INTRODUCTION}

It is generally observed that the voluntary intake of food approximately balances the animal's requirements for nutrients. This review will concentrate on the nutritional properties of food (the capacity of food to supply matter necessary for the repair of living tissues or the performance of their healthy functions (Webster, 1915)) rather than on the hedonic aspects. Voluntary food intake is the weight of food eaten in a given period of time, while appetite is the drive to eat a specific nutrient. Most of the available information concerns food intake but, where possible, drives to eat will be included in the discussion.

The concept to be developed in the present review is that the consequences of eating a meal, whether physical, chemical or psychological, feed back to the controlling centres of the brain to adjust the weight of food eaten in the short term to match the rate of utilization of those products. Some products of eating accumulate very slowly (e.g. adipose tissue), but if they have any influence on feeding must exert that influence by adding small signals to the larger signals generated by the more immediate consequences of eating (e.g. gut distension, glucose) to terminate feeding or lengthen the inter-meal interval.

If we are to 'explain' the control of intake then we must consider it from the point of view of causal relationships, and it is certainly possible to obtain from the literature quantitative relationships between two or more variables. In many cases, however, the direction of causality is difficult to determine and the only independent variable we can be sure of is time. The present review of the metabolic control of appetite and food intake will, therefore, emphasize the changes in the possible determinants of feeding during and between meals with the passage of time.

In the space available it is not feasible to encompass all aspects of the subjects of the title and particular attention will be paid to the role of nutrients and metabolites and to the involvement of metabolic hormones in the control of meal eating, with particular reference to recent findings with the laboratory rat.

\section{THE CYCLICAL NATURE OF FEEDING}

\section{THE PERIOD JUST BEFORE A MEAL}

The period preceding one meal is also, of course, the period following the previous meal. Le Magnen \& Devos (1980) found a good correlation between the weight of food eaten by rats in a meal and the interval to the next meal during the night, but no correlation with pre-meal interval, and concluded that the size of a meal is not determined by the metabolic deficit incurred before the meal. However, there are subtle changes in metabolism preceding spontaneous meals which are likely to be quite different in animals with free access to food compared with those which have to search for their next meal. Presumably the internal events which cause a free-fed animal to start to eat are similar to those which cause a predator to initiate its search for prey or a grazer to seek fresh pastures. In the rat, the species which has received most attention, there are metabolic changes which precede feeding and are thought to be involved in its initiation. Louis-Sylvestre \& Le Magnen (1980), taking jugular blood continuously from spontaneously-feeding rats, observed a small but consistent reduction in glucose concentration starting about 5 min before the onset of a meal. They suggested that this might be sufficient to act on the brain to induce feeding. Campfield et al. (1985) also found this fall (approximately 10\%) in blood glucose concentration, starting rather earlier than in the previous case and reaching a nadir around 5 min before the start of the spontaneous meal (Fig. 1).

Are these events causal or incidental to feeding? When blood glucose was automatically monitored and used to control a pump (Campfield et al. 1985), intravenous infusion of glucose solution to attenuate the pre-prandial fall in blood glucose delayed the onset of the 


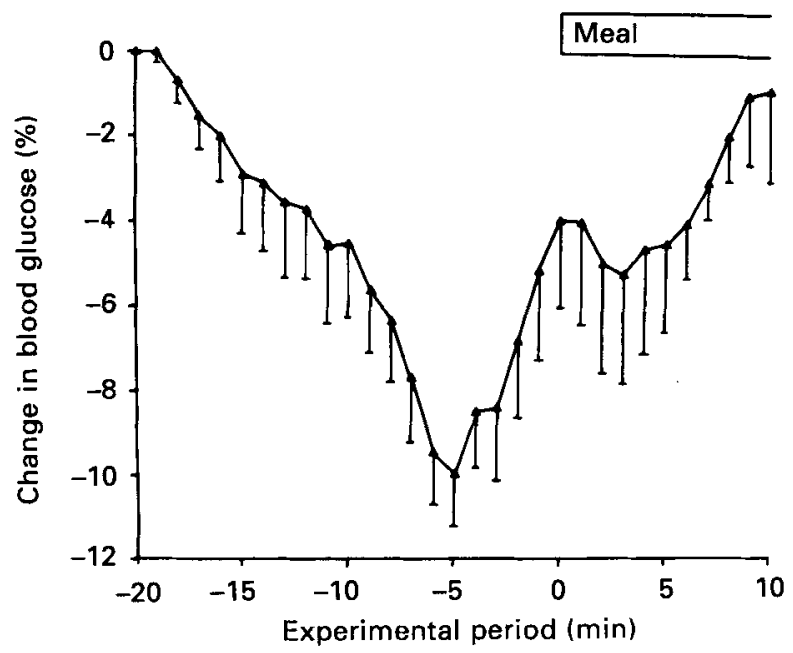

Fig. 1. Average time-course of the pre-meal decline in blood glucose concentration with the start of the meal at zero time. Average baseline glucose concentration was $1.04 \mathrm{~g} / \mathrm{l}$ (Campfield et al. 1985 ; used with permission.)

next meal from 12 to $318 \mathrm{~min}$ after the onset of the glucose decline; saline $(9 \mathrm{~g}$ sodium chloride/1) infusion had no effect. In one observation the glucose infusion was not started until after the nadir of the spontaneous fall in blood glucose concentration and the onset of the meal was not delayed. Withholding food until the glucose levels had returned to baseline prevented feeding until the next spontaneous decline in blood glucose about $1 \mathrm{~h}$ later (Campfield \& Smith, 1986). It appears, therefore, as if the actual fall in glucose may trigger feeding. These observations suggest that the glucose fall is causally involved in the initiation of a meal in the laboratory rat, but Strubbe et al. (1977) found no effect of glucose infused between spontaneous meals on meal size or duration. However, when insulin accompanies the glucose infusion suppression of feeding results (Nicolaidis \& Rowland, 1976) and insulin levels have been found to be at their lowest just before meals in rats (Strubbe et al. 1977). It seems, therefore, that glucose needs to be taken up by insulinsensitive tissues in order to be effective in depressing intake.

In the sheep spontaneous meals of a highly digestible feed were preceded by peaks of growth hormone in plasma (Driver \& Forbes, 1981). Growth-hormone secretion is a sensitive index of nutritional status and it was suggested that the pre-meal peak was an indication of the need to replenish body stores, rather than a direct cause of eating. Injection of growth hormone to mimic spontaneous peaks had no effect on feeding behaviour (P. M. Driver \& J. M. Forbes, unpublished results) so that the release of growth hormone from the anterior pituitary (under the control of the hypothalamus) and the onset of feeding seem to be independent consequences of a relative shortfall in nutrient supply from the digestive tract. The growth-hormone cycle, although being of similar periodicity to that of feeding, has recently been found not to be synchronized with it in either the rat (Mosier \& Jansons, 1987), or the goat (Tindall et al. 1978).

When animals are trained to press a bar to obtain food and the number of presses required to initiate a meal is varied, increasing the effort required to start a meal causes a reduction in the number of meals but an increase in meal size, which results in maintenance of total intake and body-weight (Collier, 1985). This illustrates that feeding is not absolutely dependent on metabolic factors but on the interaction (or additivity, see p. 161) of numerous factors. 


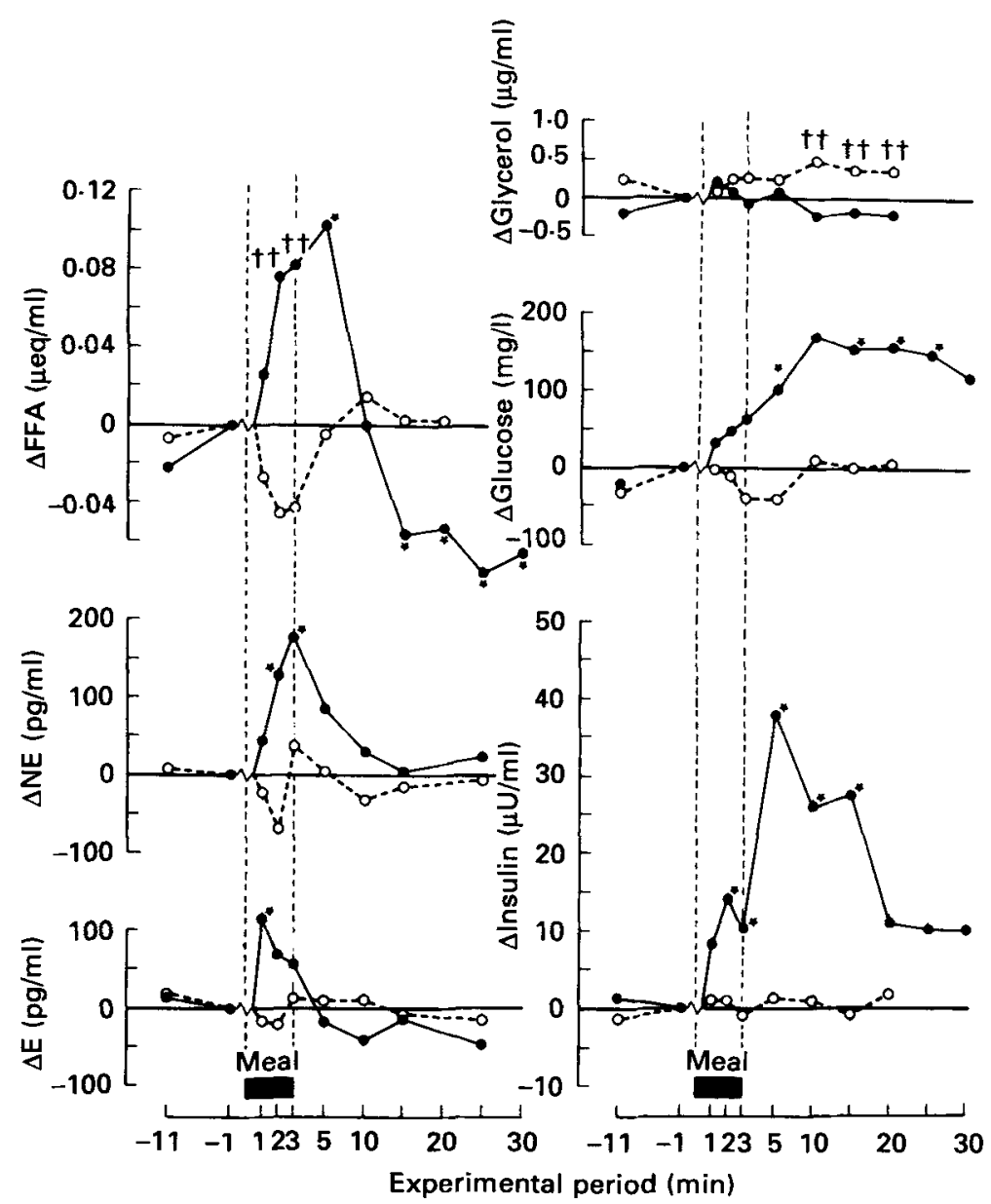

Fig. 2. Effects of food intake on plasma free fatty acids (FFA), noradrenaline (NE), adrenaline (E), glycerol, glucose and insulin in rats $(O)$; control rats without food $(O)$. Mean values were significantly different from the pre-meal level: $P<0.05$. Mean values were significantly different from control animals: $\dagger+P<0.005$. (Steffens et al. 1986; used with permission.)

\section{THE MEAL BEGINS}

The animal starts to eat at a rate which is influenced both by its nutritional status and by the palatability of the food. The rate of eating decelerates in proportion to the amount remaining to be consumed (Skinner, 1932) and later in the meal the animal might sample other feeds if more than one are available. Small pauses occur but are not indicative of the end of the meal.

Some of the changes which occur at meal onset in the rat are summarized in Fig. 2; the most obvious is an initial spurt of insulin secretion (e.g. Steffens et al. 1986). In the sheep this spurt can be induced by the sight of the food (Bassett, 1975) and this is also true of cattle (Vasilatos \& Wangsness, 1980). One effect of the insulin is to cause a short-lived decline in plasma glucose concentrations, as seen in the rat (Campfield et al. 1985) and in the sheep (Bassett, 1975).

Eating stimulates the sympathetic and parasympathetic branches of the autonomic 
nervous system (Steffens et al. 1986; Fig. 2) which, in addition to causing the insulin spurt referred to earlier, might contribute to satiety via actions on the liver (see p. 152).

The hedonic properties of foods play an important part in determining which particular food an animal prefers to eat if given a choice. The sensory impression an animal receives from its food (the palatability) also affects the rate at which the animal eats and thus the speed with which the consequences of eating occur.

When an attractive novel food is offered to rats they start to eat immediately without the transient decline in blood glucose that precedes a spontaneous meal of a familiar food (Campfield \& Smith, 1986). When fresh food is given at the same time each day to animals fed $a d$ lib, they often learn to anticipate its arrival and voluntarily fast for a few hours before eating a large meal of the fresh food; this is particularly important when the food is moist or dusty and deteriorates quickly (e.g. Driver \& Forbes, 1981). These examples illustrate again that hedonic factors can override metabolically induced hunger or satiety, at least in the short term.

In the early part of the meal the stomach is filling but there is little or no passage into the duodenum or increase in rates of absorption of substrates or metabolites. In the ruminant, however, eating stimulates the rate of contraction of the stomachs and might bring pre-existing short-chain fatty acids to the rumen wall to exert inhibitory effects there and to be absorbed at a faster rate than just before the meal.

\section{THE MEAL CONTINUES AND TERMINATES}

Numerous changes take place during the meal, some or all of which might eventually lead to satiety: distension of various sections of the digestive tract, increased osmotic pressure within the lumen of the gut, high rates of secretion of several hormones and other peptides and uptake of metabolites by liver, muscle and adipose tissue.

Many workers have concentrated on a single putative controller of intake and have had to face the problem of having to administer 'their' candidate satiety factor at several times the physiological level in order to prevent feeding. In many cases the appropriate information is not available from which to determine whether or not a particular experimental manipulation is causing a physiological change, and the methodology used in studies of feeding control can have a marked influence on the results obtained.

\section{DIGESTIVE AND METABOLIC EVENTS UNDERLYING FEEDING CONTROL}

\section{DIGESTA FLOW AND DISTENSION OF THE DIGESTIVE TRACT}

Within a few minutes of the start of the meal digesta begins to pass into the duodenum and a few minutes after that the first of the products of digestion are being absorbed. Stomach filling continues and the first signs of satiation can be observed. In the chicken food can be stored in the crop (a diverticulum of the oesophagus) which delays stomach filling but itself generates satiety signals (see Forbes, 1986).

\section{Stomach}

Non-nutrients, or 'dietary bulk' reduce the concentration of nutrients in the food so that more food is eaten before nutrient-induced satiety occurs. However, the volume accumulating in the stomach, and later passed to the intestines, may be limited by the capacity of these viscera and a physical, distention-induced satiety may result. This is particularly true in ruminant animals with foods high in fibrous constituents which have to stay in the rumen for many hours. Forbes (1986) discussed this aspect in more detail.

Reidelberger et al. (1983), using rats with gastric fistulas, found that sham feeding was 
stopped by the infusion of a liquid diet into the duodenum and concluded that stomach distension is not necessary for normal satiety with this particular type of food. However, the rate at which the stomach discharges its contents into the duodenum has an important influence on the signals generated by that part of the intestine and is partly controlled by the quantity and quality of duodenal contents. Glucose infusions into the stomach depressed intake (Gregory et al. 1987), but this effect was ascribed to intestinal osmotic or energetic effects of the glucose which delayed stomach emptying and prolonged stomach distension.

\section{Duodenum}

Glucose solutions infused into the duodenum have been shown to depress food intake in many species, e.g., rat (Novin et al. 1974), pig (Houpt et al. 1979), chicken (Shurlock \& Forbes, $1981 a$; Shaobi \& Forbes, 1987), but it is unclear whether this involves duodenal glucoreceptors (Mei, 1985) because osmotic and post-absorptive actions are also involved (see p. 151). Vagotomy at the level of the proventriculus (stomach) prevents the effects of glucose solutions infused at up to $90 \mathrm{mg} / \mathrm{min}$ into the duodenum of chickens (Shaobi \& Forbes, 1987) but as the nerve section includes fibres to and from the liver and pancreas as well as the duodenum it is not clear whether the glucose was acting primarily on the duodenum or at another site. Vagotomy also blocked the hypophagic effect of glucose solutions given during meals into the duodenum of pigs (Stephens, 1985), as did 2-deoxyD-glucose (2DG; a glucose anti-metabolite), and again the exact site of action is not clear. However, local anaesthetic given into the duodenum of pigs largely prevented the depression of intake caused by glucose infusion into the stomach (Gregory et al. 1987) which suggests that the duodenal wall contains receptors important in the control of feeding. Houpt $e t$ al. $(1983 b)$ suggested that good control over food intake in the pig could be exerted by a combination of three factors working largely in the duodenum: (1) osmotic sensitivity, which is precise but not directly related to nutritive value, (2) cholecystokinin (CCK) responses to protein and fat in duodenal digesta, (3) glucoreceptors in the intestine.

Some doubt has been cast on the relevance of glucose infusion into the duodenum to normal events accompanying feeding by McHugh \& Moran (1986) who monitored the quantities of glucose entering the duodenum of two fasted monkeys after oral or gastric administration of glucose solutions which did not depress intake; when they gave direct intraduodenal infusions of these amounts there was a significant depression of intake lasting for at least $1 \mathrm{~h}$. Can we then believe that infusions of nutrients into visceral organs are acting physiologically unless we test them against the same amounts entering those vicera naturally?

\section{Jejunum}

Chyme is likely to reach the jejunum before the end of the meal and the distension which results may play a part in the initiation and maintenance of satiety. Slow infusion of a liquid diet into the jejunum of rats caused a reduction in food intake which was not due to discomfort as no aversion to a flavour paired with this infusion was apparent (Canbeyli \& Koopmans, 1984). Jejunal infusion was more effective than duodenal infusion which was, in turn, more effective than infusion of the same amount of liquid food into the stomach. As it is likely that the yield of absorbed nutrients was at least as high following gastric or duodenal infusion it seems reasonable to interpret these results in terms of physical distension of the small intestine. Distension of a jejunal loop in the pig prevents feeding (Houpt, 1985). 


\section{OSMOLARITY}

The effects of digesta reaching the duodenum and jejunum could be mediated by stretch receptors, osmoreceptors or chemoreceptors. Although there is adequate neurophysiological evidence for receptors sensitive to several chemical types, that for osmoreceptors is weak (see Mei, 1985) despite much circumstantial evidence that they are important in the control of food intake.

Solutions of glucose or sodium chloride were infused into the duodenum of pigs shortly after the start of spontaneous meals (Houpt et al. 1983a). The extent of reduction in the size of the meal was proportional to the osmolarity of the solution infused. There was no effect on rate of eating or inter-meal interval showing that duodenal osmoreceptors participate only in the termination of feeding. Vagotomy blocked the effects of duodenal glucose or sodium chloride on feeding after $4 \mathrm{~h}$ fasts (Houpt et al. 1979) and, because portal vein or jugular vein injections were ineffective in influencing food intake, it was proposed that the nervous relay interrupted by vagotomy was from the duodenal wall. Xylose solutions, which are not absorbed, were less effective than glucose or sodium chloride (Houpt et al. 1983b) which suggested that the osmoreceptors were not on the surface of cells exposed directly to the infusate. Most of these effects could be blocked by a local anaesthetic given in the infusion so the receptors were not thought to be deeper than the mucosal layer. Stephens (1985) found that the effect of glucose solutions infused into the duodenum of the pig could be largely attenuated by pre-infusion of 2DG, showing that some of the hypophagic effect of glucose solutions infused into the duodenum is not osmotic (for discussion of intestinal glucoreceptors, see Mei, 1985).

In the chicken sorbitol and potassium chloride, which are not absorbed, had a greater effect on food intake when injected into the duodenum than did equimolar amounts of glucose (Shurlock \& Forbes, $1981 a$ ). It is likely, therefore, that osmoreception is also important in birds, although it is possible that the effects of hypertonic solutions are due to physical distension of the duodenum by the increase in volume as water is drawn from the blood. It is also worth noting that hypertonic solutions stimulate gut motility which is likely to stimulate mechanoreceptors in the gut wall. Lacy et al. (1985) concluded that the amounts of glucose needed to depress intake when infused into the duodenum of chickens were supraphysiological and had their effect osmotically.

Although solutions more hypertonic than digesta have been used in many studies, normal duodenal osmolarity can in fact become quite high, especially with liquid feeds (Houpt, 1983). Even in adult ruminants offered dry feeds osmolarity can be up to 585 mosmol $/ \mathrm{kg}$ in the duodenum but not so high lower down the intestines (Maloiy \& Clemens, 1980). It is likely, then, that the osmotic effect of digesta in the duodenum could be an important contributor to satiety under many circumstances. In work with rats, for example, Glick (1979) found that the depression in intake during a $2 \mathrm{~h}$ test period was more closely related to the osmolarity of the infusate given into the duodenum than its energy content.

\section{CARBOHYDRATE METABOLISM}

\section{Glucose}

Plasma glucose rises during the second half of the meal, peaking shortly after the meal ends (Louis-Sylvestre \& Le Magnen, 1980). According to the glucostatic theory this rise is the direct cause of satiation and there are several lines of evidence to support this idea, at least for the rat. Booth (1972a) found that intragastric administration of glucose followed by a $1 \mathrm{~h}$ fast reduced the size of the subsequent meal whereas 3-O-methylglucose (an unmetabolized analogue of glucose) had no effect, suggesting that it was the metabolic 
rather than the osmotic effect of glucose that was important. Booth (1972b) also found that fructose, which is used by the liver, was as effective as glucose in suppressing feeding, whether infused into the duodenum or the hepatic portal vein; galactose is utilized very inefficiently by the liver and was ineffective; once again 3-O-methylglucose, which enters cells but is not metabolized, had no effect on feeding when given into the hepatic portal vein.

These results imply a post-absorptive effect of glucose on feeding in addition to any effect glucose has on the digestive tract. Most tissues of the body utilize glucose but it is the central nervous system and the liver which have been implicated particularly in the postabsorptive effects of glucose on feeding (see p. 159). However, glucose alone is not sufficient to mimic normal satiety; glucose infused intravenously at $170 \%$ of the rate of utilization depressed intake by only $40 \%$, while when insulin was given simultaneously, depression was $70 \%$ (Even \& Nicolaidis, 1986); insulin alone stimulated intake.

The fact that fat and protein are also needed in the infusion to completely suppress feeding (Nicolaidis \& Rowland, 1976) shows that theories of intake control should be based on multiple macronutrient utilization rather than just on glucose and its metabolism.

\section{The Liver}

The liver is well placed to monitor the uptake of nutrients from the digestive tract and, given its role in smoothing out this erratic supply to maintain more stable plasma levels, it must be able to detect concentrations or rate of uptake of metabolites such as glucose and amino acids. There are important nervous links between the liver and the central nervous system (Anil \& Forbes, 1987) and it is perhaps surprising that little serious attention was paid to the role of the liver as a source of signals for controlling food intake until the early 1970s, following Russek's (1963) original suggestions. Glucose infusion into the hepatic portal vein depressed food intake to a much greater extent than infusion into the jugular vein (e.g. rabbit Novin et al. 1974; chicken Shurlock \& Forbes, 1981 b), an effect that is blocked by vagotomy (rat Martin et al. 1978; chicken Rusby et al. 1987). Amino acids can also affect intake via the liver (Russek, 1970; Shurlock \& Forbes, 1984; Rusby et al. 1987).

In ruminant animals very little glucose is absorbed from the digestive tract and most of that required is synthesized in the liver. Glucose infused into the portal vein (or any other site) of sheep has no effect on feeding (Baile \& Forbes, 1974; Anil \& Forbes, 1980). However, propionate, a major product of fermentation in the rumen, is used for gluconeogenesis by the liver and depresses intake much more when infused into the portal vein than into the general circulation; this effect is blocked by almost total denervation of the liver (Anil \& Forbes, 1980). The effect is also more specifically blocked by temporary anaesthetization of the splanchnic nerves or section of the hepatic branch of the vagus nerve (Anil \& Forbes, 1988).

In an attempt to explain the mechanism of the effect of glucose on the liver of the rat, Langhans et al. (1985a) examined whether the hypophagic effect of metabolites is linked to a particular step in their metabolism, principally in the liver. Whereas glycerol and malate depressed intake, their oxidation products dihydroxyacetone and oxaloacetate did not, indicating that the oxidation process itself is important. Lactate and its product of metabolism, pyruvate, depressed intake to an equal extent and as lactate is metabolized to pyruvate and as pyruvate itself is oxidized to acetyl-CoA the importance of the oxidation step is supported. When a high-fat diet was offered, lactate and pyruvate no longer showed the intake-depressing effect, but fat is known to depress pyruvate oxidation; it is likely that such an effect on pyruvate oxidation occurred in this experiment because blood levels of lactate and pyruvate remained elevated for longer after injection in rats fed on the high-fat diet than in those on a high-carbohydrate diet. 
Pyruvate, glycerol, malate and hydroxybutyrate are all oxidized by mitochondrial enzymes and 'the generation of reducing equivalents in the mitochondria may be the common feature of the hypophagic effects of these metabolites' (Langhans et al. 1985a). Most of the utilization of these substrates takes place in the liver so strengthening the case for considering a central role for liver metabolism in the control of food intake. Pyruvate and lactate increase liver-cell membrane potential (Dambach \& Friedmann, 1974), apparently as a result of their metabolism, as does alanine (rapidly transformed to pyruvate in the liver) which also depresses food intake (W. Langhans, unpublished results).

How does oxidation influence the firing rate of afferent fibres of liver nerves? Russek \& Racotta (1980) proposed that a metabolite related to glycogen causes hyperpolarization of the hepatocyte membrane and that this alters the polarization of nerve endings close to the hepatocytes, causing changes in firing rate in these neurons; this hypothesis remains to be tested. As the effects of glucose and other metabolites on the discharge frequency of hepatic vagal afferents are blocked by ouabain, an inhibitor of the sodium pump, Langhans \& Scharrer $(1987 b)$ studied the effect of intraperitoneal injection of ouabain on feeding in rats. They found a significant increase in feed intake during the few hours after injection; this was prevented by selective hepatic vagotomy but not by atropine. Langhans et al. $(1985 b)$ also found that selective hepatic vagotomy, but not atropine, prevented the effect of lactate on feeding, which was thought to be exerted via the liver. Atropine blocks the effects of acetyl choline released at parasympathetic nerve endings and these results support the contention that it is the afferent rather than the efferent fibres in the hepatic vagus which are important in the action of Na-pump activity on feeding. Ouabain also suppressed the decrease in vagal firing rate when glucose was infused into the hepatic portal vein (Niijima, 1981). Thus, evidence is being accumulated to support a hypothesis for the effects of several metabolites on feeding being by means of an oxidation step, particularly in the liver. Fig. 3 , summarizes the evidence for this hypothesis. This oxidation step changes the polarization of the hepatocyte membrane which affects the firing rate in vagal afferent fibres. These follow a route via the hepatic plexus passing to the coeliac ganglion and thence to the central nervous system via the splanchnic nerves (Tordoff et al. 1982). Information is first integrated in the nucleus tractus solitarius in the hind brain before being relayed to the hypothalamus.

Neither hepatic vagotomy nor coeliac ganglionectomy interfered with the feeding response to insulin or $2 \mathrm{DG}$ in rats that were deprived of food for $6 \mathrm{~h}$ after the injection to avoid the immediate emergency response (Granneman \& Friedman, 1984). This suggests that the liver does not initiate feeding under these conditions but is consistent with the idea that the liver is involved with the termination of feeding. There may, therefore, be an immediate neurally mediated influence of the liver and a longer-term metabolically mediated effect on feeding.

In order to test the possibility that infusions of glucose into the hepatic portal vein cause malaise, Tordoff \& Friedman (1986) paired infusions of glucose with one flavour of food and infusions of saline with another flavour. In rats with jugular catheters there was no subsequent preference for either flavour whereas the animals with portal vein catheters, in which glucose infusion depressed intake, subsequently showed preference for the flavour which had been paired with glucose infusion. Thus, not only was infusion of glucose at physiological rates not aversive, it actually formed the basis for the acquisition of a learned food preference.

There is evidence that vagotomy causes aversion to food (Sclafani \& Kramer, 1985) but this operation affects several other visceral organs in addition to the liver so that the specificity of the effect cannot be ascertained. It is clearly impossible to remove the liver to investigate the importance of that organ, but it is possible to bypass it by means of a portacaval shunt. Rats subjected to this operation showed increased intakes of solutions of 


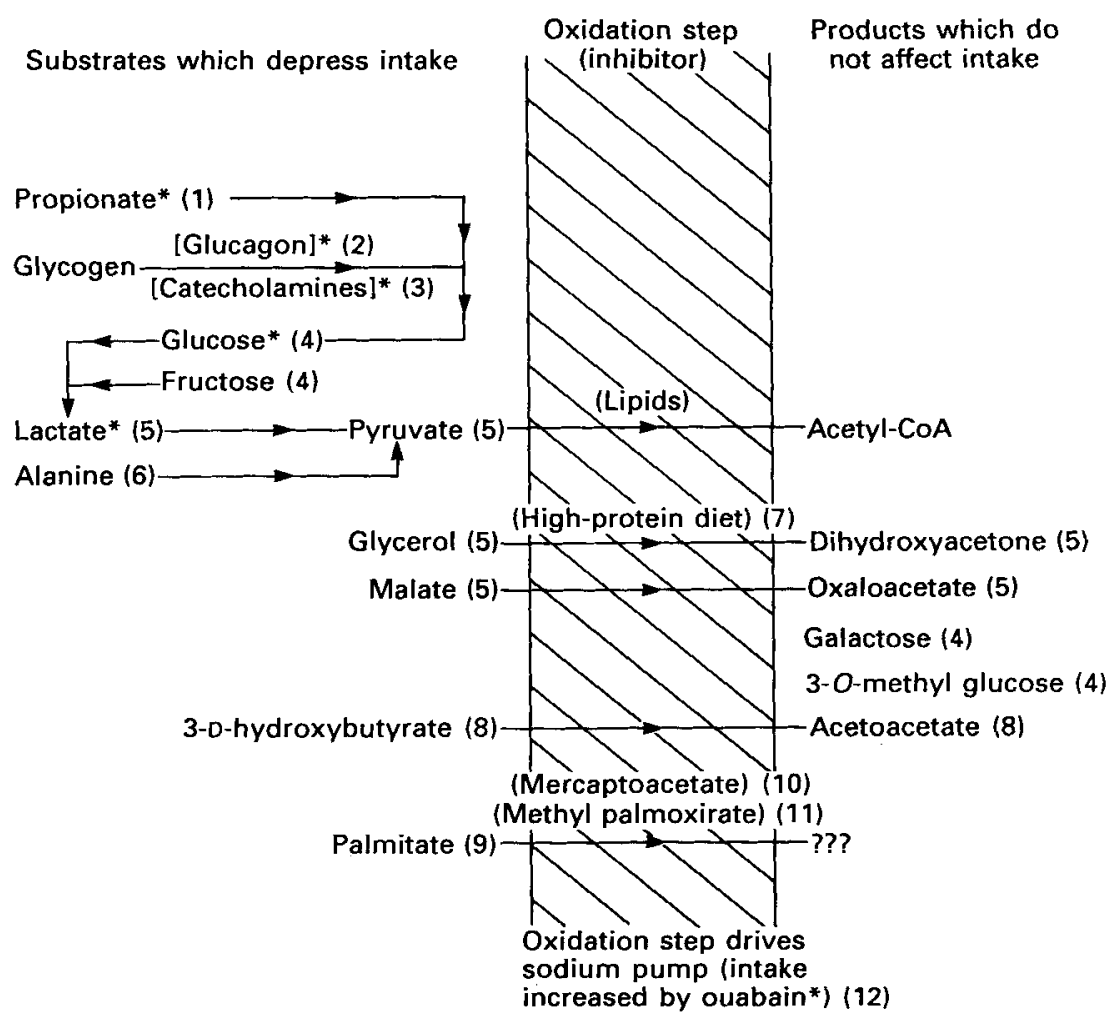

Fig. 3. Outline of some metabolic pathways in the liver and the manipulations which have been found to influence food intake. (1) Anil \& Forbes, 1980, (2) Weatherford \& Ritter, 1986, (3) Russek, 1981, (4) Booth, 1972 b, (5) Langhans et al. 1985a, (6) W. Langhans, unpublished results, (7) Langhans et al. $1984 a$, (8) Langhans et al. 1985d, (9) Vandermeerschen-Doize \& Paquay, 1984, (10) Scharrer \& Langhans, 1986;(11) Friedman et al. 1986, (12) Langhans \& Scharrer, 1987 b; ${ }^{*}$ effects which have been blocked by vagotomy.

sugars or saccharin (Martin, 1983). The fact that feeding a dietary supplement low in tryptophan prevented these increased intakes agrees with the hypothesis that an increase in the ratio, aromatic: branched-chain amino acids, such as is often seen in liver disease, can influence food intake.

Do these experimental manipulations mimic physiological control mechanisms? Several studies have failed to confirm an important role for the liver in sensing nutrients and transmitting the information via the nervous system. Thus, after $22 \mathrm{~h}$ fasts Strubbe \& Steffens (1977) found no effect of hyperglycaemia induced during feeding on meal duration or size, even when the infusion of glucose was made into the hepatic portal vein; nor did Bellinger \& Williams (1986) observe any attenuation of the glucagon-induced depression in feeding by partial or total denervation of the liver. In contrast to experiments which show clear effects of liver denervation on responses to infusions of exogenous metabolites or antimetabolites, total denervation of the liver of rats did not change any variables of spontaneous feeding between 3 and $9 \mathrm{~d}$ after surgery, nor daily intake and body-weight gains during the next 6 months (Bellinger et al. 1984); this offered no support for the concept that liver glucoreceptors are a major controller of food intake. Savory \& Hodgkiss (1984) found no differences in feeding behaviour between vagotomized and shamvagotomized chickens, whereas Rusby et al. (1987) observed no effect on total daily intake 
but significantly fewer meals, each of a larger size; liver denervation also increased meal size and inter-meal interval in rabbits (Geiselman et al. 1980) and in sheep (Anil \& Forbes, 1980), while section of the hepatic branch of the vagus of rats reduced the nocturnal bias of feeding while not affecting total daily intake (Friedman \& Sawchenko, 1984). Bellinger (1981) quotes two eminent transplant surgeons as stating that patients with transplanted livers often tend to overeat and become obese. This is what might be expected if some of the negative feedback information which normally reaches the brain can no longer do so. Conversely, liver disease is usually accompanied by hypophagia, possibly due to overstimulation of liver receptors.

Although there have been several failures to demonstrate a role for the liver in the control of feeding (for references, see Tordoff \& Friedman, 1986) work is continuing to resolve the many unanswered questions. Despite the evidence presented in this and some subsequent sections of the present review, there is still considerable controversy as to whether the liver is important in the control of intake under physiological conditions.

\section{INVOLVEMENT OF HORMONES}

\section{Insulin}

Because of the vital role of insulin in the control of utilization and storage of nutrients and metabolites it has been the subject of a great many studies on its role in the control of food intake, recently reviewed by Ritter (1986) and Woods et al. (1986).

The initial surge of insulin at the onset of feeding continues as a prolonged, nutrientrelated secretion which serves to maintain a fairly stable concentration of glucose in the blood (Louis-Sylvestre \& Le Magnen, 1980). Exogenous insulin stimulates fat deposition and food intake when given over periods of several days, accompanied by hypoglycaemia. In rats with lesions in the lateral hypothalamus, in which feeding is depressed, insulin no longer stimulates intake although it still depresses blood glucose levels (Epstein \& Teitelbaum, 1967). Insulin injection results in the termination of sham feeding in rats and this satiety seems to be a pleasant sensation because when the insulin was paired with a flavour the rats subsequently prefered that flavour (Oetting \& Vanderweele, 1985). Thus, the surge of pancreatic insulin during feeding may be an important part of the satiating signal. The hyperglycaemia caused by glucose infusion can be suppressed with appropriate doses of insulin but intake is still depressed (Woods et al. 1984), further confirming that insulin is required to induce glucose uptake in order to affect intake.

Chronic infusion of insulin is particularly effective in suppressing intake when infused into the third ventricle of the brain (Plata-Salaman et al. 1986) and it has been proposed that this is an important aspect of the physiological action of insulin (see p. 159).

\section{Glucagon}

Glucagon has also been found to increase in blood during feeding and the rapidity of this increased secretion by the pancreas suggests that it is induced by the autonomic nervous system or gut hormones, or both, rather than by changes in blood glucose concentration. Suggestions that glucagon might be involved in satiety came initially from effects of exogenous glucagon on feeding: $400 \mu \mathrm{g}$ glucagon $/ \mathrm{kg}$ given at end of $4 \mathrm{~h}$ fasts depressed intake (Vanderweele et al. 1986), but elevated peripheral venous glucagon by 10 to 150 -fold (Mclaughlin et al. 1986). Langhans et al. (1987) gave 60, 240 or $480 \mu \mathrm{g}$ glucagon $/ \mathrm{kg}$ to rats intraperitoneally and found that only the highest dose depressed intake, while all doses significantly reduced liver glycogen levels and increased hepatic vein glucose concentration to the same extent. The highest dose elevated peripheral blood glucagon levels to $30-70$ times greater than normal and the authors concluded that the effect on feeding was pharmacological. Smaller quantities $(25 \mathrm{ng})$ injected into the cerebral ventricles depressed 
intake (Inokuchi et al. 1984); this was such a small amount that it was proposed that glucagon entering the brain could participate in normal satiety. However, Langhans et al. $(1984 b)$ monitored the levels of pancreatic glucagon in the hepatic portal and hepatic veins and found that during the large meal following a $12 \mathrm{~h}$ fast, the concentration in the hepatic vein was little changed despite a doubling of the concentration in the hepatic portal vein. Thus, most of the glucagon produced under physiological conditions is taken up by the liver and is presumably partly responsible for the rapid fall in liver glycogen content that occurs during a meal (Langhans et al. 1982a); however, the catecholamines and gut hormones which are released during feeding will also play their part. This leaves the liver as the focus of attention for effects of glucagon on feeding. Injections of glucagon into the portal vein were more effective in depressing feeding than injections of the same amounts into the general circulation; furthermore hepatic vagotomy blocked the effect of $200 \mu \mathrm{g} /$ $\mathrm{kg}$ given portally during the light phase (Weatherford \& Ritter, 1986). These results provide strong circumstantial evidence for a major action of glucagon in the liver with neural transmission of information to the central nervous system. Atropine did not block the effect of glucagon on feeding (Geary \& Smith, 1983) showing that it is afferent rather than efferent fibres in the vagus which are important. Further support for vagal mediation comes from the observation that alloxan (at sub-diabetogenic doses) given into the hepatic portal vein blocked glucagon-induced suppression of feeding for 3-6 months, with subsequent recovery; this suggested that alloxan had a neurotoxic effect and thus a nervous transmission of the glucagon-induced signal (Ritter et al. 1986).

Howes \& Forbes (1987a) injected glucagon into the portal vein of cockerels in doses ranging from 5 to $1000 \mu \mathrm{g}$ and found a dose-related depression in food intake during the subsequent $90 \mathrm{~min}$. This effect was prevented by vagotomy, although interpretation of the results was somewhat clouded by the fact that control levels of feeding at the time of day the experiments were carried out were lower in vagotomized birds than intact birds.

Glucagon $(400 \mu \mathrm{g} / \mathrm{kg})$ depressed intake by rats after a $4 \mathrm{~h}$ fast during the light phase, but not at the onset of the dark phase when liver glycogen levels were low as a result of the small amount of food normally eaten during the light phase (Vanderweele et al. 1986); this suggested that substantial glycogen mobilization was necessary for the effect to be seen. When atropine was given $10 \mathrm{~min}$ before glucagon during the day the effect of the latter on feeding was prevented and it was suggested that the atropine blocked a parasympathetically mediated insulin response to glucagon. Weick \& Ritter (1986) also concluded that glucagon treatment induced an increased secretion of insulin following their observation that both 1 and $10 \mu \mathrm{g}$ glucagon $/ \mathrm{kg}$ per min given intraportally elevated blood glucose to the same extent but that there was a quicker recovery after the higher dose.

Doubt about a physiological role for glucagon in feeding control has been diminished by the finding that administration of an antiserum to glucagon stimulated intake (Langhans et al. 1982 b; McLaughlin et al. 1986). However, active immunization caused a decrease in food intake and weight gains in rats even though the plasma concentration of free glucagon was reduced (McLaughlin et al. 1984). However, total (bound + free) glucagon was greatly elevated and it might have been that the glucagon bound to plasma proteins could still affect receptors on the cell surface.

When De Castro et al. (1978) administered glucagon continuously to rats they found no effect on food intake. This may not be an appropriate method of administration, however, when it is remembered that glucagon is normally released in spurts rather than continuously.

The accumulated evidence thus indicates that a meal-induced rise in pancreatic glucagon secretion causes glycogenolysis in the liver and activation of a vagal pathway to the brain; whether this is mediated by the oxidation step referred to above is not yet clear. 


\section{Gut Peptides}

CCK is produced in the gut wall in increased amounts during and after feeding. Administration of exogenous CCK stops feeding in rats, with open stomach fistulas, which would otherwise eat for several hours (Gibbs et al. 1973); for almost a decade this was put forward as a major humoral satiety factor (e.g. Antin $e t$ al. 1975). Later it was discovered that the doses required to induce satiety for food in pigs also inhibited other activities, such as drinking (Baldwin et al. 1983), and appeared to cause abdominal discomfort in chickens (Savory \& Gentle, 1983). The dose of caerulin (CCK analogue) required to depress intake in dogs was ten times that required to stimulate pancreatic enzyme secretion (Reidelberger et al. 1986) casting further doubt on the physiological role for CCK in satiety. In view of the fact that gastric vagotomy prevents the intake-depressing effects of peripherally administered CCK (Smith et al. 1981) it is now generally accepted that this is not a satiety hormone, although it might well play some part in the visceral events leading to the termination of feeding.

CCK is produced principally in the duodenum. If its secretion in response to the presence of food is important in the control of intake then nutrients infused into the duodenum should be more satiating than those infused at more distal sites in the small intestine. Glick (1979) found no difference in the satiating effects of glucose solutions, saline or liquid food infused into these two sites and concluded that CCK is not necessary for normal responses to the presence of chyme in the intestines.

CCK is found in the brain and reduces food intake when injected intraventricularly. The possibility that CCK is a neurotransmitter involved in a physiological control was discussed by Baile et al. (1986) who concluded that 'evidence [that opioid and CCK peptides may interact to control food intake] is more suggestive than conclusive'.

\section{Catecholamines}

It has been suggested that the increased secretion of catecholamines during feeding, both from the adrenal medulla and from sympathetic nerve endings in the liver, acts as a satiety signal by its influence on glucose metabolism (Russek, 1981). In the chicken injection of up to $100 \mu \mathrm{g}$ adrenaline into the hepatic portal vein depressed intake in a dose-related manner, an effect that was totally abolished by vagotomy at the level of the proventriculus (Howes $\&$ Forbes, $1987 b$ ); these doses are likely to be well above the physiological range and the site of vagotomy affects too many organs for these results to be conclusive.

If catecholamines released by the adrenal medulla or within the liver are an important part of the system controlling intake, then blocking adrenergic receptors should influence feeding. Langhans et al. $(1985 c)$ used a wide range of doses of phentolamine and propranolol ( $\alpha$ - and $\beta$-receptor blockers) and saw no effects on spontaneous feeding, although they did block the intake-depressing effects of exogenous adrenaline. Further doubt was cast on a physiological role for adrenaline in satiety when Hinton et al. (1987) showed that adrenaline led to abnormal behaviour, including the termination of feeding, whereas injections of glucagon caused apparently-normal satiety. Coeliac vagotomy (rather than hepatic vagotomy) blocks the intake-depressing effects of adrenaline infused into the hepatic portal vein, but not that of 2DG (Tordoff \& Novin, 1982) and it can be concluded that peripheral catecholamines are not regulators of feeding behaviour in response to metabolic signals.

\section{FAT METABOLISM}

Addition of fat usually improves the palatability of a diet and it is not easy to separate the hedonic from the metabolic effects of fat on intake. In a commendable attempt to divide the two Jen et al. (1985) trained monkeys to suck liquid diets from a tube which activated 
an intragastric infusion. Thus, the ratio, fat: carbohydrate entering the stomach could be varied independently of that in the diet being taken by mouth. Gastric infusion depressed oral intake but varying the carbohydrate content of the whole food entering the stomach between 280 and $770 \mathrm{~g} / \mathrm{kg}$ and the fat between 160 and $650 \mathrm{~g} / \mathrm{kg}$ had no further effect. This suggests that the hedonic properties of high-fat diets are more important than the metabolic effects in stimulating intake.

Dietary fat is absorbed into the lymphatic system rather than into the venous drainage of the intestines in mammals and thus bypasses the liver. However, the liver is an important site of fat metabolism in mammals and also especially in birds. Intravenous infusion of fat emulsion depresses intake, an effect that is not accompanied by changes in plasma glucose or insulin concentrations (Woods et al. 1984). As animals fatten there is a gradual increase in plasma insulin concentration (Woods et al. 1974; Vandermeerschen-Doize et al. 1983); Woods et al. (1986) have reviewed the impressive evidence that this is reflected in increased concentrations of insulin in the cerebrospinal fluid which inhibit intake and thus act as a homoeostatic mechanism for body fat.

Fat is also stored in the body in large quantities, with continuous turnover which involves the release of fatty acids, glycerol and ketones such as D-3-hydroxybutyrate. There is particular interest in ways in which adipose tissue might affect feeding in view of the practical significance of preventing or reversing over-fatness, both in humans and in farm animals.

Reduction of body fat content by underfeeding is followed by overeating when food becomes freely available and overfeeding is followed by a period of hypophagia while body fat returns to pretreatment levels. This suggests that food intake is controlled by body fat content and this idea was supported by the finding that surgical removal of fat resulted in a compensatory increase in lipogenesis in rats (Liebelt et al. 1965). However, partial lipectomy of rats by Faust et al. (1977) and Gavin et al. (1984) and of chickens by Maurice et al. (1983) and Taylor \& Forbes (1988) did not result in any compensatory increase in food intake or fat deposition, suggesting that it is not total fat mass which exerts a control on intake. The possibility that adipocyte size in some way influences feeding deserves study.

\section{Glycerol}

The release of glycerol from adipose tissue is proportional to the mass of fat and the size of adipocytes. As exogenous glycerol depresses food intake (Wirtshafter \& Davis, 1977) it is possible that a lipostatic influence on feeding could be exerted by changes in glycerol concentration in plasma or uptake by a responsive tissue. Langhans et al. (1984a) used a dose of glycerol $(6.3 \mathrm{mmol} / \mathrm{kg})$ that was high enough to depress intake in rats and found plasma glucose and liver glycogen concentrations to be unaffected. This suggested that it might be the oxidation of glycerol rather than the glucose produced subsequently which was important. This idea was supported by their observation that glycerol had no effect on intake when a high-protein diet was offered; such diets are known to depress the activity of glycerol-3-phosphate dehydrogenase $(E C 1.1 .99 .5)$ activity in the liver which would reduce the rate of glycerol oxidation in that organ. While observing that plasma levels of free fatty acids, glucose, insulin and catecholamines rose during meals in the rat, Steffens et al. (1986) noted that glycerol concentration did not change and conclude that lipolysis did not increase at this time. This does not rule out a long-term effect of glycerol, added to the meal-related short-term changes in metabolism which primarily control meal size. 


\section{Ketones}

D-3-hydroxybutyrate ( $10 \mathrm{mmol} / \mathrm{kg}$ given subcutaneously) depressed food intake in rats, whereas its metabolic product, acetoacetate, did not (Langhans et al. 1985d) even though it appeared to be utilized more rapidly than D-3-hydroxybutyrate. This is consistent with the hypothesis that it is the process of oxidation of hydroxybutyrate to acetoacetate (which occurs primarily in the liver) that generates a satiating signal, in a manner analogous to the effects of oxidation of other substrates reviewed previously.

\section{Free Fatty Acids}

Infusion of long-chain fatty acids into the circulation of sheep at physiological rates resulted in depressed intake in studies by Vandermeerschen-Doize \& Paquay (1984); palmitate increased liver-cell membrane potential according to Dambach \& Friedmann (1974); this could be a way in which fat metabolism influences feeding. Injection of mercaptoacetate (which inhibits fatty acid oxidation) intraperitoneally in rats had no effect on the intake of a low-fat $(30 \mathrm{~g} / \mathrm{kg})$ diet, but greatly increased the intake of a medium-fat $(180 \mathrm{~g} / \mathrm{kg})$ diet (Scharrer \& Langhans, 1986). This effect was more potent during the day than at night, perhaps because the rate of fatty acids oxidation is normally higher during the day. It may be that another inhibitor of fatty acid oxidation, pent-4-enoate, did not affect intake in the studies by Booth \& Campbell (1975) because the diet used was quite low in fat. Section of the hepatic branch of the vagus almost completely prevented the increase in intake of a medium-fat diet (Langhans \& Scharrer, 1986) while atropinization did not block the effect, which again suggests that it is the afferent fibres of the vagus which are important in the feeding response to modification of fatty acid metabolism. Diabetic rats can oxidize dietary fat but not glucose; while normal rats showed no preference for a flavour which had been paired with glucose, compared with a flavour paired with oil, diabetic rats preferred the flavour which had been paired with oil (Tordoff et al. 1987), which they associated with an oxidizable (and therefore satiating?) food.

The chicken seems to be particularly sensitive to the effects of infused fat on feeding, which may be related to the fact that most lipid synthesis occurs in the liver and the lipid is then transported in the bloodstream. Lacy et al. (1986) found that as little as $100 \mathrm{mg}$ lipid given in suspension into the hepatic portal vein of cockerels of an egg-laying strain, over a 30 min period, depressed subsequent intake to half control levels, while similar infusion into the jugular vein was without effect. However, a much larger amount was without effect in broiler chickens of the same weight (but younger age) and these birds were also insensitive to glucose infused into the hepatic portal vein (Lacy et al. 1985). Broilers have been selected for high feed intake but the physiological consequences of this are not yet sufficiently well understood to explain the lack of effect of infused nutrients on food intake in this type of bird (Forbes, 1988).

\section{INTEGRATION OF CONTROL MECHANISMS}

\section{INVOLVEMENT OF THE CENTRAL NERVOUS SYSTEM}

Are parts of the brain themselves sensitive to glucose or insulin, or both, or do they act less directly as relays in the pathway from peripheral receptors to the intake-controlling circuits? Glucose-sensitive neurons in the lateral hypothalamus decrease their firing rate in the presence, locally, of glucose. These same neurons appear to be linked with glucosesensitive receptors in the liver, as most of the glucose-sensitive neurons in the lateral hypothalamus decreased their rate of firing when glucose was infused into the hepatic portal vein (Shimizu et al. 1983). So far as feeding is concerned, the important receptors in 
the brain are probably not glucose-specific because infusions of mannose and 3-Dhydroxybutyrate (both of which can be utilized by the brain), as well as glucose, depressed food intake in hypoglycaemic rats (Stricker et al. 1977).

Although there is incontrovertible evidence that the hypothalamus is intimately involved in the control of feeding, recent studies of the hind-brain, reviewed by Grill (1986) and Ritter \& Edwards (1986), demonstrate that the area postrema and the nucleus of the solitary tract are sensitive to glucose and capable of exerting an influence on diet selection. Reciprocal connexions exist between the hypothalamus and the caudal hindbrain which presumably form part of the neural circuitry which controls feeding.

\section{DIET SELECTION IN RELATION TO METABOLISM}

When animals have a choice between several foods each meal includes a mixture of food items, rather than each meal consisting entirely of one food. It has long been known that the overall diet which is chosen from the choice available is usually capable of sustaining normal life and the phrase 'nutritional wisdom' has been coined to describe this ability. Thus, Evvard (1915) found that pigs grew more quickly when given access to a variety of feeds than when given a single formulation. Instances of 'nutritional stupidity' have, however, been recorded, such as the pregnant ewes observed by Gordon \& Tribe (1951), which chose a wholly inappropriate mixture of feeds which resulted in loss of weight and some abortions.

An increase in energy requirements induced by thyroxine treatment caused an increase in food intake by mice, the increase being entirely due to the greater preference for starch (Donhoffer \& Vonotsky, 1947). It appears that any factor which increases the demand for energy relative to protein is likely to increase the preference for carbohydrate or fatty foods, or both, over protein-rich foods: insulin treatment of rats, which increases the rate of storage in adipose tissue, specifically increased the intake of carbohydrate (Richter, 1942; Kanarek et al. 1980) while diabetic rats selected less carbohydrate (Bellush \& Rowland, 1986). Growing broiler chicks gained weight at the same rate whether they were fed on a conventional diet or offered a choice between soya-bean meal ( $46 \mathrm{~g}$ protein $/ \mathrm{kg}$ ) and ground maize $(9 \mathrm{~g}$ protein $/ \mathrm{kg})$. As they grew from 12 to $50 \mathrm{~d}$ their total intake increased, but this was almost totally due to increased intake of maize, resulting in a reduction in the overall protein content of the selected diet from 250 to $140 \mathrm{~g} / \mathrm{kg}$, approximately matching the decline in the required protein: energy ratio (Kaufman et al. 1978).

What is the mechanism(s) whereby nutrient requirements can be expressed in terms of appetites for specific nutrients? One idea is that brain serotonin synthesis is directly affected by tryptophan uptake from blood into the brain (see Fernstrom, 1987) and alters the carbohydrate:protein ratio chosen from a selection of foods. However, Elkin et al. (1985) could find no evidence for such an hypothesis based on plasma and brain amino acid levels in chicks in which protein and energy intake had been monitored. Fernstrom (1987) has recently reviewed the work of the last decade which has attempted to elucidate the mechanisms of protein selection. He concluded that in single meals there is a connection between the serum tryptophan: large neutral amino acids ratio, and thus brain serotonin synthesis, and the ingestion of proteins and carbohydrates. However, the causality of the relationship is difficult to analyse as brain serotonin and diet selection must both be allowed to change freely in this type of experiment. Blundell \& Hill (1987) stated that experimental methods in this area have not so far been adequate, but are optimistic that it will still be fruitful to follow up the existing findings rather than abandon the approach just because of the methodological difficulties. According to Booth (1987) it will be necessary to separate the macronutrient content of the foods offered from the texture, taste or smell of these foods. 
Serotonin given into the paraventricular hypothalamic nucleus depresses intake, particularly of carbohydrate, when a choice is given (Shor-Posner et al. 1986); cyproheptadine, a serotonin antagonist, significantly stimulated intake, particularly of fat and carbohydrate. Leibowitz et al. (1985) have reported that noradrenaline injected directly into the paraventricular nucleus of the hypothalamus stimulates carbohydrate intake specifically, irrespective of its sweetness; saccharin intake was not affected. This was a prolonged effect (at least $14 \mathrm{~d}$ ) and was not accompanied by a marked increase in daily intake.

The decision as to which food to eat next is influenced by the metabolic consequences of previous intakes of the foods on offer. For example, rats show no aversion to a threoninedeficient food when it is first offered at the beginning of the light phase, when intake is low, but within $2-3 \mathrm{~h}$ of the first large meal at the onset of the dark phase their preference is definitely for the balanced diet (Leung \& Rogers, 1986).

The results of self-selection studies are very variable and the problems of experimentation and interpretation in this area have been thoroughly reviewed by Blundell (1983).

\section{INTEGRATION OF SATIETY SIGNALS}

Many of the factors thought to be involved in the control of food intake have been discussed in the present review; none of them is likely to be the only controller. How, then, are the signals from the various types of receptors integrated by the appropriate brain circuits? In discussing the role of the liver and effects of fatty acids on intake we have seen the possibility for integration of effects of several metabolites which are oxidized in the hepatocytes. Friedman et al. (1986) manipulated both carbohydrate and fat metabolism by blockage of glycolysis with $2 \mathrm{DG}$ and inhibition of fatty acid oxidation with methyl palmoxirate and observed stimulation of feeding; the two treatments given separately had very little effect. Methyl palmoxirate by itself did not affect intake of a normal diet but when a high-fat diet was given it stimulated intake in a dose-dependent manner. Combination of 2DG with nicotinic acid (which blocks lipolysis) again had a synergistic effect, stimulating intake significantly compared with very small effects of the two treatments given alone. The site(s) of action were not examined critically, but the liver may be involved as the organ is especially sensitive to methyl palmoxirate and $2 \mathrm{DG}$ is particularly effective when given into the hepatic portal vein. If the liver has a source of energy-yielding substrate (either carbohydrate or fat) it does not signal deprivation to the central nervous system.

Another experiment in which a combination of putative intake-controlling agents was studied used doses of glucagon $(100 \mu \mathrm{g} / \mathrm{kg})$, CCK $(0.15 \mu \mathrm{g} / \mathrm{kg})$ or bombesin $(0.75 \mu \mathrm{g} / \mathrm{kg})$ which did not affect meal size of a liquid diet when given separately, but combined to depress meal size by $19-40 \%$ (Hinton et al. 1986); this suggests a synergistic and not just an additive effect of low doses, although higher doses had additive effects. Gibbs et al. (1981) found additive effects of CCK and bombesin in rats deprived of food for $7 \mathrm{~h}$. An additive effect of CCK $(0 \cdot 25-0.5 \mu \mathrm{g} / \mathrm{kg})$ and bombesin $(0 \cdot 25-1.0 \mu \mathrm{g} / \mathrm{kg})$ was also seen by Stein \& Woods (1981) after $6 \mathrm{~h}$ fasts.

In the chicken, Shurlock \& Forbes $(1981 b)$ gave glucose into the crop, where it was thought to depress feeding by distension, and into the hepatic portal vein, where it acted as a metabolic stimulus, and found almost exact additivity of effects on intake. Glucose and lysine infused into the hepatic portal vein of cockerels also gave additive effects (Rusby \& Forbes, 1987). In sheep, Adams \& Forbes (1981) found that the depression in intake with moderate inflation of a balloon in the rumen was additive with that of acetate infused into the rumen at high physiological rates, as were the effects of acetate into the rumen and propionate into the portal vein. In similar work with lactating cows Anil et al. (1987) also 
found approximate additivity between the effects of rumen distension and infusion of salts of short-chain fatty acids into the rumen.

There is general agreement, then, that small experimentally induced changes in several signals that might be involved in food intake act together to reduce food intake. The sum of such small changes which occur during a spontaneous meal might be sufficient to be satiating. The considerable complexity of the system is only likely to be understood by constructing mathematical simulations to test hypotheses; simple systems which use energy as their currency have been developed by Toates \& Booth (1974) and Forbes (1980), but further sophistication should now be possible with the continued development of our ideas about the control of intake.

\section{MAINTENANCE OF SATIETY}

Those changes which occur during a meal, such as increased blood glucose and insulin levels and increased duodenal osmolarity, continue after the meal and maintain the state of satiety until they have fallen to low levels again. The events which lead to the start of the next meal then begin and the whole cycle is repeated with a frequency which depends on rates of digestion, absorption and utilization.

After feeding, rats typically display a sequence of behaviour starting with exploring and grooming and continuing with resting or sleeping. This sequence is seen following CCKinduced termination of feeding (Antin et al. 1975) and after the ingestion of glucose solutions (Kushner \& Mook, 1984). If rats 'satiated' with glucose solution are then offered normal food or powdered glucose they immediately eat significant amounts (Mook et al. 1983) showing that satiety for one food is not absolute satiety.

Protein is more satiating than carbohydrate or fat. Geary (1979) observed a greater depression of voluntary intake when a protein hydrolysate was given via a gastric cannula $(1.32 \mathrm{~J}$ metabolizable energy/ $\mathrm{J}$ infusate energy) than glucose $(0.8 \mathrm{~J}$ metabolizable energy/ $\mathbf{J}$ infusate energy which is probably related to the fact that protein has a slower flow-rate from the stomach and will give a prolonged period of intestinal stimulation.

Inhibition of fatty acid utilization with mercaptoacetate reduced the latency to eat without affecting meal size (Langhans \& Scharrer, 1987a) thus implicating fatty acid oxidation in the maintenance of satiety after a meal.

\section{PROBLEMS AND PITFALLS}

There are many instances where evidence from one or more experiments is refuted by that from others. The paradox seems to be due to several major factors.

(1) There have been differences in experimental protocol such as the type of food offered or the duration of any period of food withdrawal before an experimental treatment or observation. Most studies of peripheral feedback signals either offer food ad lib. and add the infused substance to the contents already in the gut, or precede feeding tests with fasts of many hours which put the animal in an abnormal state. Booth \& Jarman (1976) attempted to overcome these shortcomings by fasting rats for just long enough to empty the stomach $(2-3 \mathrm{~h})$. Glucose was then given into the duodenum or hepatic portal vein and $10-15 \mathrm{~min}$ were allowed for its absorption before food was replaced; the depression in intake, compared with the control, demonstrated the post-absorptive effects of glucose on feeding. The degree of stress to which animals are subjected might also influence the results of experiments on the control of intake as adrenalectomy reduces daytime intake without necessarily affecting total daily intake, while corticosterone-replacement therapy increases total and daytime intake in obese but not in lean rats (Freedman et al. 1985).

(2) There are species differences. Hamsters (Mesocricetus auratus) do not increase their food intake after a period of food deprivation while rats invariably do (Silverman \& Zucker, 1976). 
(3) There have been differences in interpretation. For example, Le Magnen \& Tallon (1966) found a close correlation between the size of a meal and the post-meal interval, using an arbitrary minimum inter-meal interval of $\mathbf{4 0} \mathrm{min}$, and proposed that the onset of feeding is determined largely by the rate of metabolic utilization of the products of the previous meal. Castonguay et al. (1986) have used an objective method, based on a sudden change in the frequency distribution of inter-meal intervals, to determine the minimum inter-meal interval and found it to be between 5 and $10 \mathrm{~min}$. Applying this criterion they failed to obtain a significant relationship between size and post-meal interval and reached a different conclusion.

\section{CONCLUSIONS}

Le Magnen \& Devos (1984) have concluded that 'the amount of food eaten from the onset to the termination of a meal, or meal size, is mainly determined by the peripheral, i.e. oral and gastrointestinal action of ingested foods. Meal to meal intervals, and therefore the meal frequency are mainly dependent on post-absorptive and metabolic factors'. Another way of putting this is to say that meal termination is not finely controlled as it seems to be induced by numerous factors acting in concert, many of which are not directly related to the eventual nutrient yield of the meal. However, the products of the meal in question can be more accurately monitored during the subsequent inter-meal interval and used to determine the onset of the next meal. The same idea is expressed by Stricker \& McCann (1985): "when eating, increasing gastric fill and increasing hepatic delivery of calories both serve to reduce the likelihood that animals will continue to feed. Once they stop eating ... they will remain satiated despite an empty stomach so long as the liver continues to get utilizable calories from the intestines'.

The present review has shown how recent evidence supports the concept that the liver generates nutrient-related signals to warn the central nervous system of impending crises which can be averted by starting or stopping feeding. Further work on the biochemical and neural aspects of this mechanism is needed.

We can no longer consider the various theories of intake control as alternatives but rather as complementary and contributing to a multifactorial control system. No single factor is essential for normal feed intake and many manipulations which stay within the physiological range have effects which can only be picked up by close attention to details of feeding behaviour. As Novin (1983) says, there are no necessities to satiety, only sufficiencies.

The author is grateful for the helpful comments of G. R. Hervey and G. H. Smith on drafts of this manuscript and for the referee's many useful suggestions.

\section{REFERENCES}

Adams, G. B. \& Forbes, J. M. (1981). Additivity of effects of ruminal acetate and either portal propionate or rumen distension on food intake in sheep. Proceedings of the Nutrition Society 40, 44A.

Anil, M. H. \& Forbes, J. M. (1980). Feeding in sheep during intraportal infusions of short-chain fatty acids and the effect of liver denervation. Journal of Physiology 298, 407-414.

Anil, M. H. \& Forbes, J. M. (1987). Neural control and neurosensory functions of the liver. Proceedings of the Nutrition Society 46, 125-133.

Anil, M. H. \& Forbes, J. M. (1988). The roles of hepatic nerves in the reduction of food intake as a consequence of intraportal sodium propionate administration in sheep. Quarterly Journal of Experimental Physiology. (In the Press.)

Anil, M. H., Forbes, J. M. \& Mbanya, J. N. (1987). Additive effects of acetate, propionate and distension of the rumen on hay intake by lactating cows. Journal of Physiology 386,61P.

Antin, J., Gibbs, J., Holt, J., Young, R. \& Smith, G. P. (1975). Cholecystokinin elicits the complete behavioural sequence of satiety in rats. Journal of Comparative and Physiological Psychology 89, $784-790$. 
Baile, C. A. \& Forbes, J. M. (1974). Control of feed intake and regulation of energy balance in ruminants. Physiological Reviews 54, 160-214.

Baile, C. A., McLaughlin, C. L. \& Della-Fera, M. A. (1986). Role of cholecystokinin and opioid peptides in control of food intake. Physiological Reviews 66, 172-234.

Baldwin, B. A., Cooper, T. R. \& Parrott, R. F. (1983). Intravenous cholecystokinin octapeptide in pigs reduces operant responding for food, water, sucrose solution or radiant heat. Physiology and Behavior 30, $399-403$.

Bassett, J. M. (1975). Dietary and gastro-intestinal control of hormones regulating carbohydrate metabolism in ruminants. In Digestion and Metabolism in the Ruminant, pp. 383-398 [I. W. McDonald and A. C. I. Warner, editors]. Armidale: University of New England Press.

Bellinger, L. L. (1981). Commentary on 'The current status of the hepatostatic control of food intake'. Appetite 2, 144-145.

Bellinger, L. L., Mendel, V. E., Williams, F. E. \& Castonguay, T. W. (1984). The effect of liver denervation on meal patterns, body weight and body composition of rats. Physiology and Behavior 33, 661-667.

Bellinger, L. L. \& Williams, F. E. (1986). Glucagon and epinephrine suppression of food intake in liver denervated rats. American Journal of Physiology 251, R349-R358.

Bellush, L. L. \& Rowland, N. (1986). Dietary self-selection in diabetic rats, an overview. Brain Research Bulletin 17, 653-661.

Blundell, J. E. (1983). Problems and processes underlying the control of food selection and nutrient intake. In Nutrition and the Brain, pp. 163-221 [R. J. Wurtman and J. J. Wurtman, editors]. New York: Raven Press.

Blundell, J. E. \& Hill, A. J. (1987). Nutrition, serotonin and appetite: Case study in the evolution of a scientific idea. Appetite 8, 183-194.

Booth, D. A. (1972a). Satiety and behavioral caloric compensation following intragastric glucose loads in the rat. Journal of Comparative and Physiological Psychology 78, 412-432.

Booth, D. A. $(1972 b)$. Postabsorptively induced suppression of appetite and the energostatic control of feeding. Physiology and Behavior 9, 199-202.

Booth, D. A. (1987). Central dietary 'Feedback onto nutrient selection': not even a scientific hypothesis. Appetite 8, 195-201.

Booth, D. A. \& Campbell, C. S. (1975). Relation of fatty acids to feeding behaviour effects of palmitic acid infusions, lighting variations and pent-4-enoate, insulin of propranolol injection. Physiology and Behavior. 15, 523-535.

Booth, D. A. \& Jarman, S. P. (1976). Inhibition of food intake in the rat following complete absorption of glucose delivered into the stomach, intestine or liver. Journal of Physiology 259, 501-522.

Campfield, L. A., Brandon, P. \& Smith, F. J. (1985). On-line continuous measurement of blood glucose and meal pattern in free-feeding rats, the role of glucose in meal initiation. Brain Research Bulletin 14, 605-616.

Campfield, L. A. \& Smith, F. J. (1986). Functional coupling between transient declines in blood glucose and feeding behavior, temporal relationships. Brain Research Bulletin 17, 427-433.

Canbeyli, R. S. \& Koopmans, H. S. (1984). Comparison of gastric, duodenal and jejunal contributions to the inhibition of food intake in the rat. Physiology and Behavior 33, $951-958$.

Castonguay, C. J., Kaiser, L. L. \& Stern, J. S. (1986). Meal pattern analysis, Artifacts, assumptions and implications. Brain Research Bulletin 17, 439-444.

Collier, G. H. (1985). Satiety, An ecological perspective. Brain Research Bulletin 14, 693-700.

Dambach, G. \& Friedmann, N. (1974). Substrate-induced membrane potential changes in the perfused rat liver. Biochimica et Biophysica Acta 367, 366-370.

De Castro, J., Paullin, S. K. \& De Lugas, G. M. (1978). Insulin and glucagon as determinants of body weight set point and microregulation in rats. Journal of Comparative and Physiological Psychology 92, 571-579.

Donhoffer, S. Z. \& Vonotsky, J. (1947). The effect of thyroxine on food intake and selection. American Journal of Physiology 150, 334-339.

Driver, P. M. \& Forbes, J. M. (1981). Episodic growth hormone secretion in sheep in relation to time of feeding, spontaneous meals and short term fasting. Journal of Physiology 317, 413-424.

Elkin, R. G., Ndife, L. I. \& Rogler, J. C. (1985). Dietary self-selection and the regulation of protein and energy intake in chicks. Physiology and Behavior 34, 743-750.

Epstein, A. N. \& Teitelbaum, P. (1967). Specific loss of the hypoglycemic control of feeding in recovered lateral rats. American Journal of Physiology 213, 1159-1167

Even, P. \& Nicolaidis, S. (1986). Short-term control of feeding, limitation of the glucostatic theory. Brain Research Bulletin 17, 621-626.

Evvard, J. M. (1915). Is the appetite of swine a reliable indication of physiological needs? Proceedings of the lowa Academy of Science 1915, 375-403.

Faust, I. M., Johnson, P. R. \& Hirsch, J. (1977). Surgical removal of adipose tissue alters feeding behavior and the development of obesity in rats. Science 197, 393-396.

Fernstrom, J. D. (1987). Food-induced changes in brain serotonin synthesis, is there a relationship to appetite for specific macronutrients. Appetite 8, 163-182.

Forbes, J. M. (1980). A model of the short-term control of feeding in the ruminant, effects of changing animal or feed characteristics. Appetite 1, 21-41.

Forbes, J. M. (1986). The Voluntary Food Intake of Farm Animals. London: Butterworths. 
Forbes, J. M. (1988). Relationships between feed intake, energy balance and adiposity. In Genetic, Metabolic and Hormonal Basis of Leanness in Domestic Birds, pp. 97-107 [B. Leclercq, editor]. London: Butterworths.

Freedman, M. R., Castonguay, T. W. \& Stern, J. S. (1985). Effect of adrenalectomy and corticosterone replacement on meal patterns of Zucker rats. American Journal of Physiology 249, R584-R594.

Friedman, M. I. \& Sawchenko, P. E. (1984). Evidence for hepatic involvement in control of ad libitum food intake in rats. American Journal of Physiology 247, R106-R113.

Friedman, M. I., Tordoff, M. G. \& Ramirez, I. (1986). Integrated metabolic control of food intake. Brain Research Bulletin 17, 855-859.

Gavin, M. L., Gray, J. M. \& Johnson, P. R. (1984). Estrogen-induced effects on food intake and body weight in ovariectomized, partially lipectomized rats. Physiology and Behavior 32, 55-60.

Geary, N. (1979). Food intake and behavioral caloric compensation after protein repletion in the rat. Physiology and Behavior 23, 1089.

Geary, N. \& Smith, G. P. (1983). Selective hepatic vagotomy blocks pancreatic glucagon's satiety effect. Physiology and Behavior 31, 391-394.

Geiselman, P. J., Martin, J. R., Vanderweele, D. A. \& Novin, D. (1980). Multivariate analysis of meal patterning in intact and vagotomized rabbits. Journal of Comparative and Physiological Psychology 94, 388-399.

Gibbs, J., Kulkosky, P. J. \& Smith, G. P. (1981). Effects of peripheral and central bombesin on feeding behavior of rats. Peptides 2, Suppl. 2, 179-183.

Gibbs, J., Young, R. C. \& Smith, G. P. (1973). Cholecystokinin elicits satiety in rats with open gastric fistulas. Nature 245, 323-325.

Glick, Z. (1979). Intestinal satiety with and without upper intestinal factors. American Journal of Physiology 236, R142-R146.

Gordon, J. G. \& Tribe, D. E. (1951). The self-selection of diet by pregnant ewes. Journal of Agricultural Science 41, 187-190.

Granneman, J. \& Friedman, M. I. (1984). Effect of hepatic vagotomy and/or coeliac ganglionectomy on the delayed eating response to insulin and $2 \mathrm{DG}$ injection in rats. Physiology and Behavior 33, $495-498$.

Gregory, P. C., McFadyen, M. \& Rayner, D. V. (1987). The influence of gastrointestinal infusions of glucose on regulation of food intake in pigs. Quarterly Journal of Experimental Physiology 72, 525-536.

Grill, H. J. (1986). Caudal brainstem contributions to the integrated neural control of energy homeostasis. In Feeding Behavior: Neural and Humoral Controls, pp. 103-129. [R. C. Ritter, S. Ritter and C. D. Barnes, editors]. Orlando: Academic Press.

Hinton, V., Esguerra, M., Farhoody, N., Granger, J. \& Geary, N. (1987). Epinephrine inhibits feeding nonspecifically in the rat. Physiology and Behavior 40, 109-115.

Hinton, V., Rosofsky, M., Granger, J. \& Geary, N. (1986). Combined injection potentiates the satiety effects of pancreatic glucagon, cholecystokinin, and bombesin. Brain Research Bulletin 17, 615-619.

Houpt, T. R. (1983). The controls of food intake in the pig. In Physiologie Digestive Chez le Porc. pp. 17-28. [J. P. Laplace, T. Corring and A. Rerat, editors]. Paris: INRA.

Houpt, T. R. (1985). Control at the gut level. Proceedings of the Nutrition Society 44, 323-330.

Houpt, T. R., Anika, S. M. \& Houpt, K. A. (1979). Preabsorptive intestinal satiety controls of food intake in pigs. American Journal of Physiology 236, R328-R337.

Houpt, T. R., Baldwin, B. A. \& Houpt, K. A. (1983a). Effects of duodenal osmotic loads on spontaneous meals in pigs. Physiology and Behavior 30, 787-796.

Houpt, T. R., Houpt, K. A. \& Swan, A. A. (1983b). Duodenal osmoconcentration and food intake in pigs after ingestion of hypertonic nutrients. American Journal of Physiology 245, R181-R189.

Howes, G. A. \& Forbes, J. M. (1987a). A role for the liver in the effects of glucagon on food intake in the domestic fowl. Physiology and Behavior 39, 587-592.

Howes, G. A. \& Forbes, J. M. (1987b). Food intake of domestic fowl injected with adrenergic agonists and antagonists into the hepatic portal vein. Pharmacology, Biochemistry and Behavior 26, 757-764.

Inokuchi, A., Oomura, Y.\& Nishimura, H. (1984). Effect of intracerebroventricularly infused glucagon on feeding behavior. Physiology and Behavior 33, 397-400.

Jen, K. L. C., Bodkin, N. L., Metzger, B. L. \& Hansen, B. C. (1985). Nutrient composition: Effects on appetite in monkeys with oral factors held constant. Physiology and Behavior 34, 655-660.

Kanarek, R. B., Marks-Kaufman, R. \& Lipeles, P. I. (1980). Increased carbohydrate intake as a function of insulin administration in rats. Physiology and Behavior 25, 779-782.

Kaufman, L. W., Collier, G. \& Squibb, R. L. (1978). Selection of an adequate protein-carbohydrate ratio by domestic chicks. Physiology and Behavior 20, 339-344.

Kushner, L. R. \& Mook, D. G. (1984). Behavioral correlates of oral and postingestive satiety in the rat. Physiology and Behavior 33, 713-718.

Lacy, M. P., Van Krey, H. P., Skewes, P. A. \& Denbow, D. M. (1985). Effect of intrahepatic glucose infusions on feeding in heavy and light breed chicks. Poultry Science 64, 751-756.

Lacy, M. P., Van Krey, H. P., Skewes, P. A. \& Denbow, D. M. (1986). Food intake in the domestic fowl, effects of intrahepatic lipid and amino acid infusion. Physiology and Behavior 36, 533-538.

Langhans, W., Damaske, U. \& Scharrer, E. (1984a). Subcutaneous glycerol injection fails to reduce food intake in rats fed on a high protein diet. Physiology and Behavior 32, 785-790. 
Langhans, W., Duss, M. \& Scharrer, E. (1987). Decreased feeding and supraphysiological plasma levels of glucagon after glucagon injection in rats. Physiology and Behavior 41, 31-35.

Langhans, W., Egli, G. \& Scharrer, E. (1985a). Regulation of food intake by hepatic oxidative metabolism. Brain Research Bulletin 15, 425-428.

Langhans, W., Egli, G. \& Scharrer, E. $(1985 b)$. Selective hepatic vagotomy eliminates the hypophagic effect of different metabolites. Journal of the Autonomic Nervous System 13, 255-262.

Langhans, W., Geary, N. \& Scharrer, E. (1982a). Liver glycogen content decreases during meals in rats. American Journal of Physiology 243, R450-R453.

Langhans, W., Pantel, K., Muller-Schell, W., Eggenberger, E. \& Scharrer, E. (1984b). Hepatic handling of pancreatic glucagon and glucose during meals in rats. American Journal of Physiology 247, R827--R832.

Langhans, W., Pantel, K. \& Scharrer, E. (1985c). Dissociation of epinephrine's hyperglycemic and anorectic effect. Physiology and Behavior 34, 457-464.

Langhans, W., Pantel, K. \& Scharrer, E. (1985d). Ketone kinetics and D-(-)-3-hydroxybutyrate-induced inhibition of feeding in rats. Physiology and Behavior 34, 579-582.

Langhans, W. \& Scharrer, E. (1986). Evidence for a vagally mediated satiety signal derived from hepatic fatty acid oxidation. Journal of the Autonomic Nervous System 18, 13-18.

Langhans, W. \& Scharrer, E. (1987a). Role of fatty acid oxidation in control of meal pattern. Behavioral and Neural Biology 47, 7-16.

Langhans, W. \& Scharrer, E. (1987b). Evidence for a role of the sodium pump of hepatocytes in the control of food intake. Journal of the Autonomic Nervous System 20, 199-205.

Langhans, W., Zieger, V., Scharrer, E. \& Geary, N. (1982b). Stimulation of feeding in rats by intraperitoneal injection of antibodies to glucagon. Science 218, $894-896$.

Le Magnen, J. \& Devos, M. (1980). Parameters of the meal pattern in rats, their assessment and physiological significance. Neuroscience and Biobehavioral Reviews 4, Suppl. 1, 1-11.

Le Magnen, J. \& Devos, M. (1984). Meal to meal energy balance in rats. Physiology and Behavior 32, 39-44.

Le Magnen, J. \& Tallon, S. (1966). Spontaneous periodicity of meal taking in the white rat. Journal of Physiology, Paris 58, 323-349.

Leibowitz, S. F., Weiss, G. F., Yee, F. \& Tretter, J. B. (1985). Noradrenergic innervation of the paraventricular nucleus, specific role in control of carbohydrate ingestion. Brain Research Bulletin 14, 561-567.

Leung, P. M. B. \& Rogers, Q. R. (1986). Effect of amino acid imbalance and deficiency on dietary choice patterns of rats. Physiology and Behavior 37, 747-758.

Liebelt, R. A., Ichinoe, S. \& Nicholson, N. (1965). Regulatory influences of adipose tissue on food intake and body weight. Annals of the New York Academy of Sciences 131, 559-582.

Louis-Sylvestre, J. \& Le Magnen, J. (1980). A fall in blood glucose level precedes meal onset in free-feeding rats. Neuroscience and Biobehavioral Research 4, Suppl, 1, 13-16.

McHugh, P. R. \& Moran, T. H. (1986). The inhibition of feeding produced by direct intraintestinal infusion of glucose. Is this satiety? Brain Research Bulletin 17, 415-418.

McLaughlin, C. A., Gingerich, R. L. \& Baile, C. A. (1984). Decreased food intakes and body weights in rats immunized against pancreatic glucagon. Physiology and Behavior 33, 723-732.

McLaughlin, C. L., Gingerich, R. L. \& Baile, C. A. (1986). Role of glucagon in the control of food intake in the Zucker obese and lean rat. Brain Research Bulletin 17, 419-426.

Maloiy, G. M. O. \& Clemens, E. T. (1980). Gastrointestinal osmolality, electrolyte and organic acid composition in five species of East African herbivorous mammals. Journal of Animal Science 51, 917-924.

Martin, J. R. (1983). Alterations in ingestive behavior following experimental portacaval anastomosis in rats. Physiology and Behavior 30, 749-756.

Martin, J. R., Novin, D. \& Vanderweele, D. A. (1978). Loss of glucagon suppression of feeding following vagotomy in rats. American Journal of Physiology 234, E314-318.

Maurice, D. V., Whisehunt, J. E., Jones, J. E. \& Smoak, K. D. (1983). Effect of lipectomy on control of feed intake and homeostasis of adipose tissue in chickens. Poultry Science 62, 1466.

Mei, N. (1985). Intestinal chemosensitivity. Physiological Reviews 65, 211-237.

Mook, D. G., Brane, J. A., Kushner, L. R. \& Whitt, J. A. (1983). Glucose solution intake in the rat, the specificity of postingestive satiety. Appetite 4, 1-9.

Mosier, H. D. \& Jansons, R. A. (1987). Lack of synchrony between feeding activity and pulsatile growth hormone secretion in rats. Physiology and Behavior 39, 183-186.

Nicolaidis, S. \& Rowland, N. (1976). Metering of intravenous versus oral nutrients. American Journal of Physiology 231, 661-668.

Niijima, A. (1981). Neurophysiological evidence for hepatic glucose-sensitive afferents. Commentary on 'The current status of hepatic theory of food intake control', Appetite 2, 151-152.

Novin, D. (1983). The integration of visceral information in the control of feeding. Journal of the Autonomic Nervous System 9, 207-220.

Novin, D., Sanderson, J. D. \& Vanderweele, D. A. (1974). The effect of isotonic glucose on eating as a function of feeding condition and infusion site. Physiology and Behavior 13, 3-7.

Oetting, R. L. \& Vanderweele, D. A. (1985). Insulin suppresses intake without inducing illness in sham feeding rats. Physiology and Behavior 34, 557-562. 
Plata-Salaman, C. R., Oomura, Y. \& Shimizu, N. (1986). Dependence of food intake on acute and chronic ventricular administration of insulin. Physiology and Behavior 37, 717-734.

Reidelberger, R. D., Kalogeris, T. J., Leung, P. M. B. \& Mendel, V. E. (1983). Postgastric satiety in the shamfeeding rat. American Journal of Physiology 244, R872-R881.

Reidelberger, R. D., Kalogeris, T. J.\& Solomon, T. E. (1986). Comparative effects of caerulein on food intake and pancreatic secretion in dogs. Brain Research Bulletin 17, 445-449.

Richter, C. (1942). Increased dextrose appetite of normal rats treated with insulin. American Journal of Physiology 135, 781-787.

Ritter, R. C. \& Edwards, G. L. (1986). Dorsomedial hindbrain participation in control of food intake. In Feeding Behavior: Neural and Humoral Controls, pp. 131-161 [R. C. Ritter, S. Ritter and C. D. Barnes, editors]. Orlando: Academic Press.

Ritter, S. (1986). Glucoprivation and the glucoprivic control of food intake. In Feeding Behavior: Neural and Humoral Controls, pp. 271-313 [R. C. Ritter, S. Ritter and C. D. Barnes, editors]. Orlando: Academic Press.

Ritter, S., Weatherford, S. C. \& Stone, S. L. (1986). Glucagon-induced inhibition of feeding is impaired by hepatic portal alloxan injection. American Journal of Physiology 250, R682-R690.

Rusby, A. A., Anil, M. H., Chatterjee, P. \& Forbes, J. M. (1987). The effects of intraportal infusion of glucose and lysine on the food intake of intact and hepatic vagotomized chickens. Appetite 9, 65-72.

Rusby, A. A. \& Forbes, J. M. (1987). Effects of infusions of lysine, leucine and ammonium chloride into the hepatic portal vein of chickens on voluntary food intake. British Journal of Nutrition 58, 325-331.

Russek, M. (1963). Participation of hepatic glucoreceptors in the control of food intake. Nature 197, $79-80$.

Russek, M. (1970). Gluco-ammonia receptors in liver. Federation Proceedings 29, 658.

Russek, M. (1981). Reply to commentary on 'Current status of the hepatostatic theory of food intake control'. Appetite 2, 157-162.

Russek, M. \& Racotta, R. (1980). A possible role of adrenaline and glucagon in the control of food intake. In Frontiers of Hormone Research, pp. 120-137 [T. B. S. Van Wimersma, editor]. Basel: Karger.

Savory, C. J. \& Gentle, M. J. (1983). Effects of food deprivation, strain, diet and age on feeding responses to fowls to intravenous injection of cholecystokinin. Appetite 4, 165-177.

Savory, C. J. \& Hodgkiss, J. P. (1984). Influence of vagotomy in domestic fowls on feeding activity, food passage, and satiety effects of two peptides. Physiology and Behavior 33, 937-944.

Scharrer, E. \& Langhans, W. (1986). Control of food intake by fatty acid oxidation. American Journal of Physiology 250, R1003-R1006

Sclafani, A. \& Kramer, T. H. (1985). Aversive effects of vagotomy in the rat. A conditioned taste aversion analysis. Physiology and Behavior 34, 721-726.

Shaobi, T. S. \& Forbes, J. M. (1987). Feeding responses to infusions of glucose solutions into the duodenum of chickens, and the influences of pre-fasting or vagotomy. British Poultry Science 28, 407-413.

Shimizu, N., Oomura, Y., Novin, D., Grijalva, C. V. \& Cooper, P. H. (1983). Functional correlations between lateral hypothalamic glucose-sensitive neurons and hepatic portal glucose-sensitive units in rat. Brain Research 265, 49-54.

Shor-Posner, G., Grinker, J. A., Marinescu, C., Brown, O. \& Leibowitz, S. F. (1986). Hypothalamic serotonin in the control of meal patterns and macronutrient selection. Brain Research Bulletin 17, 663-671.

Shurlock, T. G. H. \& Forbes, J. M. (1981 a). Factors affecting food intake in the domestic chicken, The effect of infusions of nutritive and non-nutritive substances into the crop and duodenum. British Poultry Science 22, 323-331.

Shurlock, T. G. H. \& Forbes, J. M. (1981 $b$ ). Evidence for hepatic glucostatic regulation of food intake in the domestic chicken and its interaction with gastrointestinal control. British Poultry Science 22, 333-346.

Shurlock, T. G. H. \& Forbes, J. M. (1984). Effects on voluntary intake of infusions of glucose and amino acids into the hepatic portal vein of chickens. British Poultry Science 25, 303-308.

Silverman, H. J. \& Zucker, I. (1976). Absence of post-fast food compensation in the golden hamster (Mesocricetus auratus). Physiology and Behavior 17, 271-283.

Skinner, B. F. (1932). Drive and reflex strength. Journal of General Psychology 6, 22-37.

Smith, G. P., Jerome, C., Cushin, B. J., Eterno, R. \& Simansky, K. J. (1981). Abdominal vagotomy blocks the satiety effect of cholecystokinin in the rat. Science 13, 1036-1037.

Steffens, A. B., Van der Gugten, J., Godeke, J., Luiten, P. G. M. \& Strubbe, J. H. (1986). Meal-induced increases in parasympathetic and sympathetic activity elicit simultaneous rises in plasma insulin and free fatty acids. Physiology and Behavior 37, 119-122.

Stein, L. J. \& Woods, S. C. (1981). Cholecystokinin and bombesin act independently to decrease food intake in rats. Peptides 2, 431-436.

Stephens, D. B. (1985). Influence of intraduodenal glucose on meal size and its modification by 2-deoxy-D-glucose or vagotomy in hungry pigs. Quarterly Journal of Experimental Physiology 70, 129-135.

Stricker, E. M. \& McCann, M. J. (1985). Visceral factors in the control of food intake. Brain Research Bulletin 14, 687-692.

Stricker, E. M., Rowland, N., Saller, C. F. \& Friedman, M. I. (1977). Homeostasis during hypoglycemia: Central control of adrenal secretion and peripheral control of feeding. Science 196, 79-81. 
Strubbe, J. H. \& Steffens, A. B. (1977). Blood glucose levels in portal and peripheral circulation and their relation to food intake in the rat. Physiology and Behavior 19, 303-307.

Strubbe, J. H., Steffens, A. B. \& De Ruiter, L. (1977). Plasma insulin and the time pattern of feeding in the rat. Physiology and Behavior 18, 81-86.

Taylor, C. G. \& Forbes, J. M. (1988). Food intake and growth of broiler chickens following removal of the abdominal fat pad. Proceedings of the Nutrition Society. (In the Press.)

Tindall, J. S., Knaggs, G. S., Hart, I. C. \& Blake, L. A. (1978). Release of growth hormone in lactating and nonlactating goats in relation to behaviour, stages of sleep, electroencephalograms, environmental stimuli and levels of prolactin, insulin, glucose and free fatty acids in the circulation. Journal of Endocrinology 76, 333-346.

Toates, F. M. \& Booth, D. A. (1974). Control of food intake by energy supply. Nature 251, 710-711.

Tordoff, M. G. \& Friedman, M. I. (1986). Hepatic portal glucose infusions decrease food intake and increase food preference. American Journal of Physiology 251, R192-R196.

Tordoff, M. G. \& Novin, D. (1982). Coeliac vagotomy attenuates the ingestive responses to epinephrine and hypertonic saline but not insulin, 2 deoxy-D-glucose or polyethylene glycol. Physiology and Behavior 29, 605-613.

Tordoff, M. G., Novin, D. \& Russek, M. (1982). Effects of hepatic denervation on the anorexic response to epinephrine, amphetamine and lithium chloride, a behavioral identification of glucostatic afferents. Journal of Comparative and Physiological Psychology 96, 361-365.

Tordoff, M. G., Tepper, B. J. \& Friedman, M. I. (1987). Food flavour preferences produced by drinking glucose and oil in normal and diabetic rats: Evidence for conditioning based on fuel oxidation. Physiology and Behavior 41, $481-487$.

Vandermeerschen-Doize, F., Bouchat, J. C., Bouckoms-Vandermeir, M. A. \& Paquay, R. (1983). Effects of longterm ad libitum feeding on plasma lipid components and blood glucose, $\beta$-hydroxybutyrate and insulin concentrations in lean adult sheep. Reproduction, Nutrition, Développement 23, 51-63.

Vandermeerschen-Doize, F. \& Paquay, R. (1984). Effects of continuous long-term intravenous infusion of longchain fatty acids on feeding behaviour and blood components of adult sheep. Appetite 5, 137-146.

Vanderweele, D. A., Macrum, B. L. \& Oetting, R. L. (1986). Glucagon, satiety from feeding and liver/pancreatic interactions. Brain Research Bulletin 17, 539-543.

Vasilatos, R. \& Wangsness, P. J. (1980). Changes in concentrations of insulin, growth hormone and metabolites in plasma with spontaneous feeding in lactating dairy cows. Journal of Nutrition 110, 1479-1489.

Weatherford, S. C. \& Ritter, S. (1986). Glucagon satiety, diurnal variation after hepatic branch vagotomy or intraportal alloxan. Brain Research Bulletin 17, 545-550.

Webster, N. (1915). A Dictionary of the English Language, Springfield, Mass: Merriam.

Weick, B. G. \& Ritter, S. (1986). Dose-related suppression of feeding by intraportal glucagon infusion in the rat. American Journal of Physiology 250, R676-R681.

Wirtshafter, D. \& Davis, J. D. (1977). Body weight reduction by chronic glycerol treatment. Science 198, 1271-1274.

Woods, S. C., Decke, E. \& Vasselli, J. R. (1974). Metabolic hormones and regulation of body weight. Psychological Reviews 81, 26-43.

Woods, S. C., Stein, L. J., McKay, L. D. \& Porte, D. (1984). Suppression of food intake by intravenous nutrients and insulin in the baboon. American Journal of Physiology 247, R393-401.

Woods, S. C., Porte, D., Strubbe, J. H. \& Steffens, A. B. (1986). The relationships among body fat, feeding, and insulin. In Feeding Behavior: Neural and Humoral Controls, pp. 315-327 [R. C. Ritter, S. Ritter and C. D. Barnes, editors]. Orlando: Academic Press. 